\title{
Young people's participation in service evaluation
}

\author{
Michael Gaffney and Jenny Munro, with Ben Inns, Damian Morgan-Hudson, \\ Kymberley Kennedy, Lisa Nyman and Marina Buckley
}

Dr Michael Gaffney works as an independent researcher and evaluator based in Dunedin. He previously spent 15 years at the Children's Issues Centre at the University of Otago. Jenny Munro is a Senior Practitioner at the Otago Youth Wellness Trust, Dunedin. Ben Inns, Damian Morgan-Hudson, Kymberley Kennedy, Lisa Nyman and Marina Buckley are young people enjoying life to the max.

\section{Abstract}

The Otago Youth Wellness Trust is a charitable organisation that has been operating for 15 years in Dunedin, New Zealand. It decided to evaluate the wraparound service it provided to young people in the community. The young people are referred by other agencies, including schools, and are usually deemed to be in need of significant support. In this article, members of a Youth Advisory Group (YAG), describe the experience of being involved in this service evaluation project. The YAG was made up of a small number of 'service users' who developed methods for engaging young people as evaluation participants. Overall we reported positive experiences, but there was a steep learning curve for all of us to navigate the evaluation process. This article demonstrates that it is possible for young people to have a significant influence in service evaluation.

\section{Introduction}

The Otago Youth Wellness Trust (OYWT) provides a free community-based service to young people. The integrated service, or wraparound service (Bruns, et al. 2004), is delivered by a professionally qualified multi-disciplinary team of staff using a modified HHEADSS assessment (Cohen, Mackenzie and Yates 1991) and casework model that is outcomes-focused. HHEADSS in this modified form is an acronym for Home, Health, Education (or Employment), Adolescent offending, Drugs and alcohol, Sexuality and Suicidality. The young people who come into the service are aged 11-18 with complex and multiple needs and do not easily access mainstream health and social services. The service is responsible for responding to significant truancy in the city and this is a key means of referral for young people to the organisation.

The organisation was able to secure funding from the New Zealand Lottery Community Sector Research Fund to conduct a two-year service evaluation. The aim was to develop an evaluation framework that would support the service to deliver improved outcomes to all stakeholders, including: those in key government youth policy positions; government funders of the service; referrers of young people to the service; other service providers, who are working with the same young people; those who work for the organisation; and, most importantly from our perspective, the young people and their families who participate in the service. At the time of writing this article a final report for the project was not yet 
available. This article describes our experiences of including young people in the decision making within service evaluation.

\section{Youth participation in research}

A key theme in the areas of childhood studies and children's rights is having young people and children become more involved in those activities that will affect them (Lansdown 2010). In Aotearoa New Zealand we have seen this approach adopted as one of the six principles of the Youth Development Strategy Aotearoa (Ministry of Youth Affairs 2002). Not only is it important for adults to make these opportunities available, they must also be made more meaningful and relevant. In the context of research this presents some challenges, because research participation is not a widely shared experience, not everyone values research in the same way and not all research takes the same form. Yet developing children and young people's skills and understandings as researchers (Bland, Carrington and Brady 2009) and evaluators (Johnson 2010) is an emerging topic in disciplines such as youth development. For researchers and evaluators there is the extra challenge of developing youth-centred research methods (Barker and Weller 2003).

\section{The challenge of engagement and participation}

What could 'youth participation' in research look like for young people who experience multiple disadvantage and structural constraints in their lives? What do adults need to consider when marginalisation or disengagement from school is common, relationships with family/whānau are fraught, health concerns loom large and a lack of financial and social resources are ever present? Even though these young people may choose to participate there are limits around their resources or ability to always sustain the levels of participation usually demanded by such activities. The challenge for researchers is, therefore, to create 'meaningful participation' and a working relationship with young people such that their voices are heard despite ongoing difficulties. It means resourcing young people to enable participation, supporting their capacity and competency, and in some instances responding to unexpected happenings when they are buffeted by life.

Time is pivotal to ensuring the participation of young people who are more likely to be excluded from opportunities to make key decisions in relation to their lives. It is also important in creating a safe space where there is a willingness by adults to share power. It requires researchers to be open to the experience that Pillow (2003) describes as reflexivities of discomfort. These reflexivities demand that researchers pay attention to the politics of producing knowledge so that the process allows young people's voices to be heard. Writing this article with young people as co-authors has meant Michael and Jenny reflecting on and interrogating our practices as researchers (Nairn, Munro and Smith 2005). Below we describe some of our experiences and understandings of supporting the evaluation process.

\section{Service evaluation}

All stakeholders had a view on the evaluation questions: What are we doing? and Are we doing it well? One aim of the evaluation was to make sure that each group had the opportunity to provide their perspective. The project Steering Group of seven, made up of members both internal and external to the organisation, was overseeing the project with 
Jenny Munro and Michael Gaffney having responsibility for accessing the voices of young people and their families. The voices of other groups were relatively easy to access and being mainly adult professionals they tend to be more articulate in evaluation contexts than young people and their families. Our challenge was to think of ways to make sure that the voices of young people were not lost in the midst of a broader chorus. The Steering Group had decided to work with the well-established notion that evaluation is used to improve not prove (Shufflebeam and Shinkfield 1985). For our evaluation methodology we were drawn to empowerment evaluation (Fettersman and Wandersman 2005), stories of significant change (Dart and Davies 2003) transformative evaluation (Mertens 2009) and developmental evaluation (Patton 2011).

A key concern was to pay close attention to the ethical issues that arose in the evaluation process by: using a reflective approach and one that was iterative; using a relational method of inquiry with awareness of power differentials; using structured and unstructured techniques to ensure different viewpoints were represented; and being collaborative, inclusive and attuned to process throughout (Gallagher 2008; Valentine,1999). However, the challenges in achieving these things in practice only emerged as we went along (Gaffney and Munro 2012). We started by having the project reviewed by a regional health ethics committee. Beals (2012) describes the challenges of mixing participatory research and participatory youth development. Research participation is generally built on confidentiality and anonymity, whereas youth development seeks to connect voices and faces (identification). In this current study some of these issues were resolved by not having the YAG participants involved as evaluation participants who provided the data. Thus this article does not report directly on young people's views as service users, but on young people's experience of supporting service evaluation.

Even writing this article based on a collective experience poses challenges with respect to voice and authorship. With Jenny and Michael having more writing experience it is easy for the chapter to reflect their ideas and interpretations, especially once it was given a theoretical overlay. In the first few paragraphs where we try to connect with our anticipated audience, other adults, it becomes more difficult to retain the collective authorship and voice of young people. The authorship is mixed throughout the chapter in recognition of this tension. A point of reflection for you, as the reader, is to consider how you might have resolved these concerns if you had written this article.

We have listed as authors, with their consent, all members of the YAG who contributed to this article. Ideally, with enough time, it is possible to be iterative in the writing. There is always a tension in finding a balancing point that acknowledges contribution and allows people to manage their own voice. Some people have had more opportunities than others to review the chapter. After the YAG members agreed to contribute to this article as a group, Jenny spoke with them individually about their experience and it is these views that are presented below. The young people were excited about the prospect of being named authors in this writing.

\section{Setting up a Youth Advisory Group}

The role of the 'advisory' group was not prescribed ahead of their participation. Caseworkers within the organisation were asked to nominate young people whom they considered 
had a level of confidence and competence to be able to promote their ideas within a group setting. From the nine nominated, six took up the offer, four young women and two young men. At the time of their nomination, two were engaged in the organisation and four were former 'clients'. As this was a new experience for the group, we suggested that participants review their participation consent 'as they go', rather than try and decide 'up front' as to whether they wanted to commit themselves to a two-year project. Five YAG members were available to contribute to this article at the time of its writing.

YAG members did not know what their involvement in a research project would mean. Until one has been involved in research and evaluation, it is very difficult to know 'what you are letting yourself in for'.

I didn't really know what I was getting myself in for. I just did it out of a sense of 'you scratch my back and I will scratch yours'. You know, 'you help me and I will help you' (Damian).

In the beginning I thought, I envisioned, we would be providing insight on what it is like to be a teenager and us trying to help Otago Youth Wellness understand how our minds work, but eventually I realised it was coming up with a good process to understand a young person's experience of Youth Wellness (Lisa).

These understandings evolve over time. Thus it was important to offer positive experiences to support their learning. A number of the group reflected on a sense of obligation to do something in return for the help they had received. This was also the reason given by some of the evaluation participants when they decided whether to take part. While ethics focuses on voluntary participation (without coercion), much of young people's involvement was based on a sense of obligation and reciprocity from their earlier engagement with OYWT.

It would seem more correct to say that ethical participation is about the quality of the relationships, rather than being voluntary or informed. The relational element acknowledges that consent is a continually negotiated process rather than a one-off agreement (Clarke, Boorman and Nind 2011). This is important given the limits to being informed. As lead researchers Jenny and Michael still wanted participation to be voluntary and informed, as much as it could be (even though the group was not contributing data), and we wanted to be certain that we, as adults, were not abusing young people's desire to 'give back'. This aim can be complicated by the tendency of young people to comply with adult requests as a form of unintended coercion (Valentine 1999).

When potential YAG members asked about what sort of things they would be doing, Michael and Jenny answered that: it was about supporting OYWT to improve the way it worked with young people and by finding the best way to get the information from young people who had been through the service. The dilemma then was that we could not be more definite as it was for the YAG to work out the detail and design. Being informed was less important than being reassured that they would be treated with respect. All they had to go on was their previous experience with the organisation.

Young people were able to describe their experience of 'casework'. They discussed the ethical and methodological challenges of obtaining previous and current clients' understandings of casework. Based on YAG members' understandings, we developed a design for participant recruitment of young people and whanau into the evaluation. We worked on setting up and 
trialling questionnaires and survey designs. Together we formulated an analysis framework for the data received. The data, which was collected by Jenny, came from the interviews with 22 young people and 20 family members or other significant adults in their lives. We 'telephone surveyed' 73 young people and 49 family or significant others. What we learnt from this work is another story, with the final report of the evaluation still in preparation.

\section{The youth experiences on YAG}

We looked at what we enjoyed about participating in the project that has gone into its third year. We all enjoyed the experience of being involved in the project even though we were unsure about what we were being asked to do or unsure of what evaluation research was all about:

I liked meeting everyone 'cos we' re all so different. I was just nervous 'cos I was not sure what was involved, but I was also excited about it (Marina).

We enjoyed the regular 'routine' of meeting every couple of weeks, especially for the first year of the project. Getting together provided 'something to look forward to', especially food:

You mean besides the toastie pies? It was quite nice to hear other people's opinions on things about Youth Wellness. The length of time [of the project] didn't matter. Having the regular times for meeting were important when I was having a shit time at school, going to the Youth Advisory Group meant my whole day was not a waste of time (Ben).

It was appropriate for me at the time, but I would be interested at a different level [if I was to do it again]. I would like to be more productive. You needed to work harder at building up the atmosphere of the group - holding a good energy in the group to give objectives, discipline and momentum (Lisa).

Members of the YAG enjoyed the opportunity to get to know others in the organisation, whilst participating in the evaluation. The OYWT service, as set up, is about each caseworker developing a relationship with an individual young person, but the outcome is that the young people never really get a sense of others who might be accessing the service. Kymberley, for example, said:

It was good to discuss with people, who were in the same situation as me, about having a caseworker (Kymberley).

And it seemed the composition of the YAG, itself, was recognised as being good because it was diverse in terms of the age, gender and interests of the participants. Ben said:

There were quite a few girls, but if there had been more guys there might've been less input 'cos we don't really share our feelings much (Ben).

The feedback suggested that the YAG experience was a good one, and people were happy to get together. One person suggested having a larger group and a better selection process:

A wider range would've been better. Maybe more in the group, 3 or 5 more. It would be at its best if all people were engaged in the process - maybe having older people, a bit more selective.

The mix of females and males is important (Marina). 
While there were many common experiences across the group members, it was also important to remember that the casework experience was unique and so the views that were expressed in the YAG also varied.

Lastly, Michael and Jenny were interested in what young people learnt about research. Some said:

I already knew about research and understood the aims (Kymberley).

That there is a shit load involved! And there are so many ways you can approach it (Marina).

We were pleased that the young people could pick up on the complexity of doing research. For some, it was harder to identify what they had learnt about 'research' per se, of which this project was an example.

\section{What could have been improved?}

Jenny and Michael talked about trying to find the balance between recognising the volunteerism in the YAG so that it was not 'all about the work' even though we had plans for what we wanted to achieve each session. Often a particular session was important for initiating the next part of the project. There were mixed views about whether the right level of structure was provided as part of facilitation:

It would have been good to bring people back on the topic at hand and to focus more (Kymberley).

It got us more interested in turning up by not having too much structure. I think it was a good balance between fun and structure (Ben).

Gallagher (2008) talked about some of the tensions in creating a space for participation that allows for children's agency, resistance and inclusion. What is missing from this analysis is how to generate a 'we' from the 'mes' present in the group. What was enough structure for one person was too constrained for another. Our response was to allow for diverse forms of engagement that could change from meeting to meeting. Nairn, Higgins and Sligo (2007) reflected on a similar challenge for peer researchers in allowing them to take the initiative in the field or comply with the design and formats agreed upon. Fortunately qualitative methods tend to allow for more emergent processes to be acceptable.

Young people respond better to adults who show an ethic of reciprocity and the capacity to create and hold appropriate boundaries that then supports a balance between humour and strictness (Holland, Thomson, Henderson, McGrellis, \& Sharpe 2004). Meaning firm, but fair, as well as less formal.

We are teenagers, it was unavoidable. No one would've come if it was too serious and there was no humour (Damian).

When asked for improvements, the following suggestions were offered:

It would be good to give the group a bit more responsibility to try and inform what we were 
doing, e.g. to go away and do some homework, or our own research on something to bring back to the group (Lisa).

There was a six-year spread in the ages of those in the group. One of the younger members wondered if she had been too young to make a contribution. She was in her second year at high school. She was a current client of the OYWT when the group was formed, so her involvement in YAG also complemented the casework and the older female members of YAG were seen as role models for her. She said:

I enjoyed meeting older girls in the group, but I was a bit too young and I felt a bit shy and naïve, especially as I was still going through the process of having a caseworker at the time. Listening to what they said helped me. I liked where their heads were at - where they were in life, also their opinions. They were more reflective when looking back (Kymberley).

At times YAG members said that it was hard to stay involved because of what was happening in their lives, and this made it difficult to maintain a commitment.

\section{The challenges}

The researchers tried to find a balance between letting the young people set the pace and getting the group together often enough to provide timely information for the evaluation. Jenny said:
The process of contacting members of the group was sometimes quite difficult for a variety of reasons. These were often around such things as: not having money on their cell phone; being sick or others in the family being sick who needed their care; being unable to commit to coming to a meeting too far out from the arranged date because of day-to-day life events. I always phoned or texted them the day before, or on the day of a scheduled meeting to check out if they could attend. For a couple of group members there was often uncertainty around being able to get transport to OYWT. This was because they had no money for a bus fare or there was no parent able to provide transport. This meant I would pick them up and drop them off home (Jenny).

As facilitators, Jenny and Michael decided that if the project was going to make sense as a process then the YAG members needed to be able to follow through the various elements of decision-making that held it together. This allowed us to have discussions about the ethical considerations because it was a meaningful part of the context. For example, we talked about the possibility of interviewing both young people and a family member to extend our understanding of how family life contributes to young people's difficulties and how it is also a means of support. The YAG was sure that some young people would not participate if they thought their parents or carers would be approached.

A client's privacy is important. Respecting that if a kid doesn't want their parent to know everything that is going on in the programme then they have a right to keep that within the group (Damian).

To maximise participation, their suggestion was to let each young person decide if they wanted a parent or parents to be interviewed and if not, then to nominate who else they might find acceptable (if there was anyone). This resulted in us using the term 'significant other' to refer to the adults whom we interviewed or surveyed. 
There were not wild disagreements within the group about decisions, which was assisted by an iterative process giving us enough time to try things. This project grew from twoyears to three years (but not solely because of the delays in working with young people). If we had to work to deadlines, as is often the case in contracted research, it would have been much more difficult to remain authentic within the process (Munford and Sanders 2003).

One of the features of guiding collaboration within a group is learning that not everyone has to contribute in the same way. This means that the facilitator does not have to involve all participants in all aspects of the research. Instead, they can work together, drawing on people's differing strengths and inclinations, providing opportunities for new learning and engaging with a team member's willingness to contribute.

\section{Where to next for Otago Youth Wellness Trust?}

The success of the YAG has led senior people within the organisation to ask if there is an ongoing role for a regular group like this to provide feedback, with a view to improving caseworker practice and organisational management. Previous attempts to get 'conventional' feedback using postal surveys, once young people had left the service, were relatively unsuccessful. Yet, many young people willingly participated in the evaluation project, either over the phone or face to face, out of a spirit of reciprocity. They wanted to give something back to the organisation that had helped them in a difficult time, but questionnaires sent by post were not as well received as being able to speak with someone.

The advantage of an internal evaluation project like this study was that, as issues and learning emerged, there was no need to wait for a published report. Findings could be immediately shared with the caseworkers at the OYWT and be used in ongoing discussions. This meant that practice within OYWT continued to evolve as it always has done - using information and understandings from a range of sources. Having systematic feedback come directly from young people, however, sharpened the focus of those discussions. The sharing of that feedback was always done with the anonymity of the young people maintained.

\section{Conclusion}

How did the larger evaluation benefit from having a Youth Advisory Group? On paper their contribution would appear to go back via the Steering Group of which Michael and Jenny were members. And certainly this happened with continual updates to the Steering Group on how ideas being generated were influencing that element of the work. However, with Jenny leading data collection from young people and families there was also a direct link into the project process. Thus, in addition to the sub-cultural capital (Nairn et al. 2007) that the YAG has as clients (current or former) of OYWT, it was also important that young people could follow the developments between the information and guidance that they were providing and the process of evaluation design and data collection. Providing an indepth or authentic experience for young people participating in evaluation was the basis for YAG members gaining a critical understanding of the process upon which to base their contribution.

We leave you with a final comment from an advisory group participant that shows that young people want to contribute to research. In this project that contribution made a 
significant difference. We encourage you to give young people a chance to do the same in your evaluation work.

I enjoyed giving back. I felt like I was supporting what I found was so beneficial for me for making a difference in my life (Lisa).

Acknowledgements. We acknowledge the Lottery Community Sector Research Fund of New Zealand for funding the service evaluation, which then made this project with young people possible.

\section{References}

Barker, J., \& Weller, S. (2003). 'Is it fun?': Developing children centred research methods. International Journal of Sociology and Social Policy 23(1): 33-58.

Beals, F. (2012). Moving beyond the academic doors: Addressing ethical issues in NGO youth research. Youth Studies Australia 31(3): 35-42.

Bland, D., Carrington, S., \& Brady, K. (2009). Young people, imagination and re-engagement in the middle years. Improving Schools 12: 237-248.

Bruns, E.J., Walker, J.S., Adams, J., Miles, P., Osher, T.W., Rast, J., VanDenBerg, J.D. and the National Wraparound Initiative Advisory Group (2004). Ten principles of the wraparound process. Portland, OR: National Wraparound Initiative, Research and Training Center on Family Support and Children's Mental Health, Portland State University. Online. Retrieved from http:/ / www.nwi.pdx.edu/.

Clarke, G., Boorman, G., \& Nind, M. (2011). 'If they don't listen I shout, and when I shout they listen': hearing the voices of girls with behavioural, emotional and social difficulties. British Educational Research Journal 37(5): 765-780.

Cohen, E., Mackenzie, R.G., \& Yates, G.L. (1991). HEADSS, a psychosocial risk assessment instrument: Implications for designing effective intervention programmes for runaway youth. Journal of Adolescent Health 12: 539-544.

Dart, J.A., \& Davies, R. (2003). A dialogical, story-based evaluation tool: The most significant change technique. American Journal of Evaluation 24: 137-155.

Fettersman, D.M., \& Wandersman, A. (Eds.) (2005). Empowerment evaluation principles in practice. New York: Guilford Press.

Gaffney, M., \& Munro, J. (2012). Young people's participation in service evaluation. In J. Fleming \& T. Boeck (Eds.). Involving children and young people in health and social care research. Oxon, UK: Routledge: 138-148.

Gallagher, M. (2008) 'Power is not an evil': rethinking power in participatory methods. Children's Geographies 6 (2): $137-150$.

Holland, J., Thomson, R., Henderson, S., McGrellis, S., \& Sharpe, S. (2000). Catching on, wising up and learning from your mistakes: Young people's accounts of moral development. International Journal of Children's Rights 8: 271-294.

Johnson, V. (2010). 'Rights through evaluation and understanding children's realities'. In B. Percy-Smith \& N. Thomas (Eds.) A handbook of children and young people's participation: Perspectives from theory and practice. London: Routledge.

Lansdown, G. (2010). 'The realisation of children's participation rights: Critical reflections'. In B. Percy-Smith and N. Thomas (Eds.) A handbook of children and young people's participation: Perspectives from theory and practice. London: Routledge.

Mertens, D.M. (2009). Transformative research and evaluation. New York: Guildford Press.

Ministry of Youth Affairs (2002). Youth development strategy Aotearoa. Wellington: Ministry of Youth Affairs.

Munford, R. and Sanders, J. (2003). Action research. In C. Davidson and M. Tolich (Eds) Social science research in New Zealand: Many pathways to understanding (2nd ed.). Auckland: Pearson Education in New Zealand: $263-274$.

Nairn, K., Higgins, J., \& Sligo, J. (2007). Youth researching youth: 'Trading on' subcultural capital in peer research methodologies. Teachers College Record, 16 pages. Date of Publication June 09, 2007. Retrieved from www.tcrecord. org, ID number: 14515.

Nairn, K., Munro, J., \& Smith, A. B. (2005). A counter-narrative of a 'failed' interview. Qualitative Research 5(2): $221-244$.

Patton, M.Q. (2011). Developmental evaluation: Applying complexity concepts to enhance innovation and use. New York: Guilford Press.

Pillow, W. (2003). Confession, catharsis, or cure? Rethinking the uses of reflexivity as methodological power in qualitative research. Qualitative Studies in Education 16(2): 175-96.

Shufflebeam, D.L., \& Shinkfield, A.J. (1985). Systematic evaluation. Boston: Kluwer-Nijhoff.

Valentine, G. (1999). Being seen and heard? The ethical complexities of working with children and young people at home and at school. Ethics, Place E Environment 2(2): 141-155. 